\title{
Определение содержания карбоновых кислот в производственных растворах пьезоэлектрическими датчиками модифицированными полимерами с молекулярными отпечатками
}

\author{
(C) 2020 Королёв А.И. ${ }^{1}$, Заварыкина С.А. ${ }^{1}$, Као Ньят Линь ${ }^{2}$, \\ Никитина С.Ю. ${ }^{3}$, Зяблов А.Н. ${ }^{1}$ \\ ${ }^{l}$ ФГБОУ ВО «Воронежский государственный университет», Воронеж \\ ${ }^{2}$ Совместный Российско-Вьетнамский тропический научно-исследовательский \\ и технологический центр, Вьетнам \\ ${ }^{3}$ ФББОУ ВО «Воронежский государственный университет инженерных технологий», Воронеж
}

Поступила в редакцию 2.03.2020 г.

DOI: $10.17308 /$ sorpchrom.2020.20/2782

В работе разработаны пьезоэлектрические сенсоры на основе полимеров с молекулярными отпечатками для определения карбоновых кислот в газовой фазе. Цель работы состояла в разработке способа пьезосенсорного определения карбоновых кислот в паровоздушной смеси над раствором этилового спирта.

Модификацию пьезоэлектрических сенсоров проводили полимерами с молекулярными отпечатками полученными на основе ароматического сополимера $1,2,4,5$ - бензолтетракарбоновой кислоты с 4,4'-диаминодифенилоксидом. В результате были получены сенсоры с селективными покрытиями: ПМО-Acetic, ПМО-Propionic, ПМО-Butyric. Для всех полученных сенсоров характерны низкие величины относительного стандартного отклонения (не более 6\%). При этом предел обнаружения карбоновых кислот составил $1 \cdot 10^{-7}$ ммоль/дм ${ }^{3}$, а диапазон определяемых концентраций $1 \cdot 10^{-1}-1 \cdot 10^{-6}$ ммоль/дм ${ }^{3}$. Полученные градуировочные графики имеют линейный вид и коэффициент детерминации более $98 \%$ для всех разработанных ПМО-сенсоров.

В работе установлено, что модифицированные сенсоры избирательно реагируют только на те карбоновые кислоты, которые были использованы в качестве шаблонов при их синтезе. Это позволило апробировать эти сенсоры при анализе промежуточных фракций этанола: дистиллята, эпюрата, кубовой жидкости и сивушного спирта. Показано, что кубовая жидкость содержит все три карбоновые кислоты в незначительном количестве. В дистилляте и сивушном спирте содержится масляная кислота, при этом наибольшее содержание примесей карбоновых кислот зафиксирована в промежуточной фракции эпюрата.

Ключевые слова: полимеры с молекулярными отпечатками, ПМО, уксусная кислота, пропионовая кислота, масляная кислота, пьзосенсоры.

\section{Введение}

В последние годы в мире наблюдается повышенный спрос на этиловый спирт. Лидерами по его производству выступают США, Таиланд, Канада, Бразилия, Китай. Этиловый спирт применяется во многих сферах деятельности человека, особенно в пищевой промышленности, медицине и косметологии. Кроме того, увеличился спрос на этанол при изготовлении биотоплива, активно используемого почти во всем мире. Производят этанол, как правило, из картофеля, зерновых, сахарной патоки или мелассы, виноградных и других продуктов богатых углеводами [1]. 
Состав сырья, полупродуктов и готовой продукции спиртового и ликероводочного заводов может часто изменяется. Наиболее полную информацию о составе можно получить, используя непрерывный автоматический контроль, который пока не на всех предприятиях организован. В связи с этим химические лаборатории спиртовых и ликероводочных заводов проводят в начале отбор проб сырья, вспомогательных материалов, промежуточных продуктов, готовой продукции и затем анализируют их[2].

Спирт содержит в качестве примесей около семидесяти различных веществ: спиртов, альдегидов, сложных эфиров, органических кислот и др. [3]. Так производство ректификованного этилового спирта сопряжено с появлением уксусной, масляной, пропионовой и других кислот, ухудшающих органолептические свойства этанола и оказывающих негативное влияние на здоровье человека. Широкое применение карбоновых кислот и их производных в различных областях промышленности определяет актуальность совершенствования методов их определения в различных средах. В настоящее время для оценки химического состава технологических сред используют, как правило, хроматографические методы требующие дорогостоящего оборудования, стандартных растворов и высокой квалификации обслуживающего персонала[4]. В связи с чем возникает необходимость в разработке простых, надежных и дешевых экспресс-способов контроля содержания примесей в технологических растворах на различных этапах производства продукта. Эта задача может быть решена с использованием пьезоэлектрических сенсоров, селективность которых достигается модифицированием поверхности их электродов различными сорбентами, в частности полимерами с молекулярными отпечатками (ПМО) [5].

В связи с этим, цель работы состояла в разработке пьезосенсорного способа определения карбоновых кислот в производственных растворах пьезоэлектрическими датчиками модифицированными полимерами с молекулярными отпечатками.

\section{Эксперимент}

Эксперимент проводили на оригинальной установке, разработанной на кафедре аналитической химии Воронежского государственного университета, состоящий из USB-частотомера MP732, портативного генератора и пьезоэлектрического сенсора.

В работе использовали пьезоэлектрические резонаторы РК 170, с собственной частотой колебаний 4000 Гц. производства ОАО «Пьезокварц», г. Москва. Для модификации поверхности их электродов применяли продукт АД-9103 ТУ-6-19-283-85 производства ОАО МИПП НПО «Пластик», г. Москва, представляющий собой раствор полиамидокислоты (ПАК) - ароматический сополимер 1,2,4,5- бензолтетракарбоновой кислоты с 4,4'-диаминодифенилоксидом в ДМФА с массой элементарного звена - 418 у.е. и содержанием карбоксильных групп 4.78 ммоль/г сухого вещества [69]. В качестве шаблонов были выбраны карбоновые кислоты: уксусная, масляная и пропионовая [10].

Для получения полимеров с молекулярными отпечатками карбоновых кислот готовили предполимеризационную смесь, состоящую из шаблона и полиимида, которую наносили на электрод сенсора и поводили термическую имидизацию в две стадии: в течение 1 часа при температуре $80^{\circ} \mathrm{C}$, затем в течение 30 минут при температуре $180^{\circ} \mathrm{C}$. По окончании термоимидизации пьезосенсор помещали на 24 часа в дистиллированную воду для удаления молекул-темплата. В результате были получены сенсоры с селективными покрытиями: ПМО-Acetic, ПМО-Propionic, ПМО-Butyric.

Королёв и др. / Сорбционные и хроматографические процессы. 2020. Т. 20. № 2. С. 271-276 
Апробацию полученных сенсоров проводили на промежуточных фракциях получения этанола: сивушном спирте, бражном дистилляте, эпюрате и кубовой жидкости.

Бражный дистиллят крепостью 65\%об. представляет собой целевой продукт бражной колонны, получаемый при переработке бражки из зернового сырья. Эпюрат крепостью $25 \%$ об. является целевым продуктом эпюрационной колонны, получаемый путем ректификации бражного дистиллята. Кубовые жидкости ректификационной и разгонной колонн, используемые для технологических целей, содержащие следовые количества этилового спирта. Сивушный спирт состоит из смеси одноатомных спиртов и является побочным продуктом брожения при производстве этилового спирта [11].

При определении карбоновых кислот (уксусной, пропионовой, масляной) использовали метод градуировочного графика. Для этого готовили растворы кислот в диапазоне концентраций $1 \cdot 10^{-1}-1 \cdot 10^{-6}$ моль/дм ${ }^{3}$ и приводили в равновесие со своим насыщенным паром.

Сенсор закрепили в горизонтальном положении. С помощью частотомера регистрировали сигнал $\left(\mathrm{F}_{1}\right)$. После чего микрошприцем прокалывали резиновую пробку емкости, содержащей исследуемый раствор с его паром, и отбирали $5 \mathrm{~cm}^{3}$ паровоздушной смеси. Затем вводили ее в инжектор и регистрировали сигнал $\left(\mathrm{F}_{2}\right)$ в течении 10 с. Конструкция ячейки позволяла вводить анализируемую паровую смесь непосредственно на поверхность электрода сенсора. Эксперимент повторяли начиная с минимальной концентрации. Рассчитывали разность частот $\Delta \mathrm{F}$ колебаний сенсора с холостой $\left(\mathrm{F}_{1}\right)$ и анализируемой $\left(\mathrm{F}_{2}\right)$ пробой по формуле: $\Delta \mathrm{F}=\mathrm{F}_{1}-\mathrm{F}_{2}$. Градуировочный график строили в координатах $\Delta \mathrm{F}-(-\lg \mathrm{C})$.

\section{Обсуждение результатов}

В работе [4] была показана принципиальная возможность определения карбоновых кислот в жидких средах. Однако в процессе производства спирта более актуальным является контроль содержания мешающих примесей в паровоздушной фазе. В связи с этим стандартные растворы карбоновых кислот и промежуточные фракции получения этилового спирта приводили в равновесие со своим насыщенным паром.

Для всех полученных ПМО-сенсоров градировочные графики исследуемых карбоновых кислот имеют линейный вид с коэффициентом детерминации более $98 \%$.

В ходе работы определены метрологические характеристики полученных ПМО-сенсоров (табл. 1). Предел обнаружения уксусной, масляной, пропионовой кислот составил $1 \cdot 10^{-7}$ ммоль/дм ${ }^{3}$. Относительное стандартное отклонение не превышает $6 \%$.

Таблица 1. Метрологические характеристики определения карбоновых кислот сенсорами на основе ПМО

\begin{tabular}{|c|c|c|c|c|}
\hline Сенсор & $\begin{array}{c}\text { Анализируемое ве- } \\
\text { щество }\end{array}$ & $\begin{array}{c}\text { Диапазон определяемых } \\
\text { концентраций, ммоль/дм }\end{array}$ & $\begin{array}{c}\mathrm{C}_{\min } \\
\text { ммоль/дм }\end{array}$ & $\mathrm{Sr}, \%$ \\
\hline ПМО-Acetic & Уксусная кислота & $1 \cdot 10^{-1}-1 \cdot 10^{-6}$ & $1 \cdot 10^{-7}$ & 5.8 \\
\hline ПМО-Propionic & $\begin{array}{c}\text { Пропионовая кис- } \\
\text { лота }\end{array}$ & $1 \cdot 10^{-1}-1 \cdot 10^{-6}$ & $1 \cdot 10^{-7}$ & 3.7 \\
\hline ПМО-Butyric & Масляная кислота & $1 \cdot 10^{-1}-1 \cdot 10^{-6}$ & $1 \cdot 10^{-7}$ & 3.1 \\
\hline
\end{tabular}

Правильность определения карбоновых кислот в паровоздушных смесях пьезосенсорами на основе ПМО проверена методом «введено-найдено». Результаты 
представлены в таблице 2. Показано, что сенсоры на основе полимеров с молекулярными отпечатками избирательно реагируют только на те карбоновые кислоты, которые были использованы в качестве шаблонов при их синтезе. Проведенные исследования по определению карбоновых кислот в паровоздушных смесях пьезосенсорами на основе ПМО позволили апробировать их при анализе промежуточных фракций этанола: дистиллята, эпюрата, кубовой жидкости и сивушного спирта (табл. 3).

Таблице 2. Определение карбоновых кислот в паровоздушных смесях методом «введено-найдено»

\begin{tabular}{|c|c|c|c|}
\hline \multirow{2}{*}{ Аналит } & \multicolumn{2}{|c|}{ C, ммоль/ дм ${ }^{3}$} & \multirow{2}{*}{$\mathrm{S}_{\mathrm{r}}, \%$} \\
\hline & Введено & Найдено & \\
\hline \multicolumn{4}{|c|}{ Сенсор на основе ПМО -Acetic } \\
\hline \multirow{2}{*}{ Уксусная кислота } & 0.01 & $0.01 \pm 0.0006$ & 6.0 \\
\hline & 0.00001 & $0.00001 \pm 0.000001$ & 4.8 \\
\hline Пропионовая кислота & 0.0001 & - & - \\
\hline Масляная кислота & 0.0001 & - & - \\
\hline \multicolumn{4}{|c|}{ Сенсор на основе ПМО - Propionic } \\
\hline \multirow{2}{*}{ Пропионовая кислота } & 0.001 & $0.00102 \pm 0.00003$ & 2.7 \\
\hline & 0.0001 & $0.00001 \pm 0.000001$ & 5.9 \\
\hline Уксусная кислота & 0.00001 & - & - \\
\hline Масляная кислота & 0,00001 & - & - \\
\hline \multicolumn{4}{|c|}{ Сенсор на основе ПМО - Butyric } \\
\hline \multirow{2}{*}{ Масляная кислота } & 0.01 & $0.01 \pm 0.0004$ & 3.2 \\
\hline & 0.0001 & $0.0001 \pm 0.0002$ & 2.9 \\
\hline Уксусная кислота & 0.00001 & - & - \\
\hline Пропионовая кислота & 0.00001 & - & - \\
\hline
\end{tabular}

Таблица 3. Апробация ПМО-сенсоров при определении карбоновых кислот в производственных растворах

\begin{tabular}{|c|c|c|c|c|}
\hline \multirow{2}{*}{ Фракция } & Кубовая жидкость & Эпюрат & Дистиллят & $\begin{array}{c}\text { Сивушный } \\
\text { спирт }\end{array}$ \\
\cline { 2 - 5 } & Сенсор на основе ПМО-Acetic & - \\
\hline $\begin{array}{c}\text { Уксусная } \\
\text { кислота }\end{array}$ & $0.000012 \pm 0.000005$ & $0.000013 \pm 0.000004$ & - & - \\
\hline \multicolumn{7}{|c|}{ Сенсор на основе ПМО-Propionic } & - \\
\hline $\begin{array}{c}\text { Пропионо- } \\
\text { вая кис- } \\
\text { лота }\end{array}$ & $0.000013 \pm 0.000003$ & - & $0.0009 \pm 0.00004$ & $0.003518 \pm 0.0002$ \\
\hline $\begin{array}{c}\text { Масляная } \\
\text { кислота }\end{array}$ & $0.000001 \pm 0.0000007$ & $0.104 \pm 0.009$ & 0.009 на основе ПМО-Butyric & - \\
\hline
\end{tabular}

Установлено, что кубовая жидкость содержит все три карбоновые кислоты в незначительном количестве. В дистилляте и сивушном спирте содержится масляная кислота, при этом, наибольшее содержание примесей карбоновых кислот зафиксировано в промежуточной фракции эпюрата.

\section{Заключение}

В работе установлено, что разработанные пьезосенсоры с отпечатками карбоновых кислот способны определять целевые молекулы в паровоздушной фазе. При 
этом показано, что сенсоры на основе ПМО чувствительны только к той кислоте, которая была шаблоном при их синтезе. Таким образом, внедрение пьезосенсоров в технологическую линию этилового спирта позволит контролировать наличие посторонних примесей в режиме реального времени.

\title{
Список литературы
}

1. Яровенко В.Л. Справочник по производству спирта. Сырье, технология и технохимконтроль. М. Легкая и пищевая промышленность. 1981. $336 \mathrm{c.}$

2. Фертман Г.И. Химико-технологический контроль спиртового и ликеро-водочного производства. М. Пищевая промышленность. $1975.440 \mathrm{c}$.

3. Колесов С.В., Резяпов Р.Н., Куколев Б.Л., Гриненко В.А. // Вестник Башкирского университета. 2002. № 2. С.43-45.

4. Као Ньят Линь, Дуванова О.В., Никитина С.Ю., Зяблов А.Н. // Заводская лаборатория. Диагностика материалов. 2019. Т. 85. № 4. С. 11-16.

5. Као Ньят Линь, Акимова М.Г., Зяблов А.Н. // Сорбиионные и хроматографические проиессы. 2019. Т. 19. № 1. С. 30-36.

6. Соколова С.А., Дьяконова О.В., Емельянов Д.Е., Дуванова О.В. и др. // Технологии и товароведение сельскохозяйственной продукиии. 2013. № 1. С. 114-119.

7. Дьяконова О.В., Зяблов А.Н., Котов В.В., Елисеева Т.В. и др. // Сорбиионные и хроматографические процессы. 2005. Т. 5. № 4. С. 501-506.

8. Дьяконова О.В., Соколова С.А., Зяблов А.Н., Жиброва Ю.А. // Сорбиионные и хроматографические проиессы. 2007. Т. 7. № 5. С. 873-877.

9. Krivonosova I.A., Duvanova O.V., Zyablov A.N., Sokolova S.A. et al. // Butlerov Communications. 2015. T. 42. № 6. C. 152-157.

10.Као Ньят Линь, Зяблов А.Н. // Сорбиионные и хроматографические прочессы. 2018. T. 18. № 3. C. 415-422.

11.Зяблов А.Н., Говорухин С.И., Дуванова О.В., Селеменев В.Ф. и др. // Аналитика и контроль. 2014. Т. 18. № 4. С. 438-441.

\section{Determination of the content of carboxylic acids in industrial solutions by piezoelectric sensors based on polymers with molecular imprints}

\author{
(C) 2020 Korolev A.I. ${ }^{1}$, Zavarykina S.A. ${ }^{1}$, Cao Nhat Linh', \\ Nikitina S.Yu. ${ }^{3}$, Zyablov A.N. ${ }^{1}$ \\ ${ }^{I}$ Voronezh State University, Voronezh \\ ${ }^{2}$ Vietnam-Russia Tropical Centre, Vietnam \\ ${ }^{3}$ Voronezh State University of Engineering Technology, Voronezh
}

The study is dedicated to the development of piezoelectric sensors based on molecularly imprinted polymers used to determine carboxylic acids in the gas phase. The aim of the work is to develop a piezoelectric method of identifying carboxylic acids in an air-vapour mixture above an ethanol solution.

Piezoelectric sensors were modified by molecularly imprinted polymers produced from aromatic copolymer 1,2,4,5-benzene tetracarbonic acids with 4,4'-diaminodiphenyloxide. As a result, the following sensors with selected coatings were produced: MIPs-Acetic, MIPs-Propionic, MIPs-Butyric. All sensors were characterised by low values of standard deviation (within 6\%). At the same time, the detection limit of carboxylic acids was $110^{-7} \mathrm{mmol} / \mathrm{dm}^{3}$, and the range of determined concentrations was $110^{-1}-1 \cdot 10^{-6} \mathrm{mmol} / \mathrm{dm}^{3}$. The obtained graduation graphs are linear and the coefficients of determination is over $98 \%$ for all the developed MIP-sensors.

It was established that the modified sensors only react selectively to the carboxylic acids that were used as templates during synthesis. It made it possible to test these sensors to analyse intermediate ethanol fractions: distillate, epurate, still liquor, and fusel alcohol. It was shown that still liquor has a small amount of all of the three carboxylic acids. The distillate and fusel alcohol contain butyric acid, and the largest impurity content of carboxylic acids is present in the intermediate fraction of epurate.

Keywords: molecularly imprinted polymers, MIPs, acetic acid, propionic acid, butyric acid, piezosensors 


\section{References}

1. Yarovenko V.L., Ustinnikov B.A., Bogdanov Yu.P., Gromov S.I. Light and food industries, $1981,336 \mathrm{p}$.

2. Fertman G.I. Khimiko-tekhnologicheskii kontrol' spirtovogo i likero-vodochnogo proizvodstva M., Food industry, 1975. 440 p.

3. Kolesov S.V., Rezyapov R.N., Kukolev B.L., Grinenko V.A., Bulletin of Bashkir University, 2002, No 2, pp.43-45.

4. Cao Nhat Linh, Duvanova O.V., Nikitina S.Yu., Zyablov A.N., Industrial Laboratory. Diagnostics of Materials, 2019, No 4, pp. 11-16.

5. Cao Nhat Linh, Akimova M.G., Zyablov A.N., Sorbtsionnye $i$ khromatograficheskie protsessy, 2019, Vol. 19, No 1, pp. 30-36.

6. Sokolova S.A., D'yakonova O.V., Emel'yanov D.E., Duvanova O.V. et a., Technologies and commodity science of agricultural products, 2013, No 1, pp. 114-119.

Королёв Александр Игоревич - студент кафедры аналитической химии, воронежский государственный университет, Воронеж.

Заварыкина Светлана Александровна студент, кафедры аналитической химии, Воронежский государственный университет, Воронеж.

Као Ньят Линь - к.Х.Н., ассистент-исследователь, Приморское отделение, Совместный Российско-Вьетнамский тропический научноисследовательский и технологический центр, Вьетнам

Никитина Светлана Юрьевна - д.т.н. доцент кафедры машины и аппараты пищевых производств, Воронежский государственный университет инженерных технологий, Воронеж.

Зяблов Александр Николаевич - д.Х.н. профессор кафедры аналитической химии, Воронежский государственный университет, Воронеж.
7. D'yakonova O.V., Zyablov A.N., Kotov V.V., Eliseeva T.V. et al., Sorbtsionnye i khromatograficheskie protsessy, 2005, Vol. 5, No 4, pp. 501-506.

8. D'yakonova O.V., Sokolova S.A., Zyablov A.N., Zhibrova Yu.A. Sorbtsionnye i khromatograficheskie protsessy, 2007, Vol. 7, No 5, pp. 873-877.

9. Krivonosova I.A., Duvanova O.V., Zyablov A.N., Sokolova S.A. et al., Butlerov Communications, 2015, Vol. 42, No 6, pp. 152-157.

10. Cao Nhat Linh, Zyablov A.N. Sorbtsionnye i khromatograficheskie protsessy, 2018, Vol. 18, No 3, pp. 415-422.

11. Zyablov A.N., Govorukhin S.I., Duvanova O.V., Selemenev V.F.. et al., Analytics and control, 2014, Vol. 18, No 4, pp. 438-441.

Korolev Alexader I. - Student, department of analytical chemistry, Voronezh State University, Voronezh. e-mail: darer2306@yandex.ru

Zavarykina Svetlana A. - student, department of analytical chemistry, Voronezh State University, Voronezh. e-mail: zavarykina.sveta@mail.ru

Cao Nhat Linh - PhD in Chemistry, Research assistant, Coastal Branch, Vietnam-Russia Tropical Centre, Vietnam. e-mail: cnlinh0812@gmail.com

Nikitina Svetlana Yu. - Doctor of technical sciences, associate professor, department of machines and devices for food production, Voronezh State University of Engineering Technology, Voronezh. e-mail: sunik@mail.ru

Zyablov Alexander N. - Dr.Sci. (Chemistry), professor, department of analytical chemistry, Voronezh State University, Voronezh. e-mail: alex-nz@yandex.ru 